\title{
Wear performance of ductile iron after electrolytic plasma hardening
}

\author{
A. Ayday $^{1}$, M. Durman ${ }^{2}$ \\ ${ }^{1}$ Sakarya University, Faculty of Engineering, Department of Metallurgical and Materials Engineering, \\ Sakarya 54187, Turkey \\ ${ }^{2}$ Beykoz University, Faculty of Engineering and Architecture, Kavacık Campus, Istanbul 34805, Turkey
}

Received 14 February 2018, received in revised form 27 September 2018, accepted 3 October 2018

\begin{abstract}
This study aimed to improve the tribological behavior of electrolytic plasma treated (EPT) ductile iron (DI). For this purpose, ductile iron was electrolytic plasma hardened under different processing parameters (treatment time and thermal cycle). Three different types of specimens were tested: untreated DI, electrolytic plasma hardened DI and remelted DI by two type wear test. It was found that remelted DI performed much better concerning wear resistance than the other samples. The microstructure of the hardened specimens was investigated using optical microscopy. Microhardness profiles and surface hardness were investigated via the Rockwell test. The microstructure and hardness of the EPT hardened layer were dependent on the processing parameters, with the hardness values reaching the range $880-1080$ $\pm 10 \mathrm{HV}_{0.2}$.
\end{abstract}

K e y wo rds: electrolytic plasma hardening, ductile iron, hardness, remelting, wear

\section{Introduction}

In many industrial components, (e.g., roll, cam, and crankshaft, etc.) it is often required that the material is hardened at the surface while the interior of the material must remain soft or ductile. The higher hardness at the surface layer imparts excellent wear resistance, while the soft inner core provides higher toughness and fracture resistance. Hardness, strength and wear resistance can be improved using different surface treatments, such as induction, flame hardening, electron beam and more recent technologies such as laser and electrolytic plasma hardening [1-6]. However, electrolytic plasma hardening stands out for several good reasons. Short treatment times, low distortion, large part modification and eco-friendly heating are all positive features of the technique [7-9].

The modified layer on the surface of the bulk material is obtained after rapid heating and cooling or quenching by electrolytic plasma hardening. Therefore hardness of metallic materials increases compared to the rest of the untreated material. During the electrolytic plasma hardening process, the surface of the heat affected zone in the irradiated material is microstructurally transformed into austenite $[2,7$, 11]. This part is called high voltage effect (impulse). By quenching this heated layer in electrolytic solution quench the surface layer is transformed to form a martensitic structure which is harder than the base metal. This part is called low voltage effect (pause). When one impulse and one pause are completed it is called one thermal cycle or one cycle; the cycle determines the total treatment time [7-9].

In the present work, DI was electrolytic plasma hardened under different processing parameters (treatment time and thermal cycle) to produce a hardened layer with a different surface morphology. The electrolytic plasma hardening process has resulted in two surface formations, surface hardening layers, and surface remelting layers. The purpose of this study was to determine the possible correlation between wear resistance and hardness variation with microstructural changes under increasing wear loads.

\section{Experimental procedure}

The chemical composition of DI is $3.22 \% \mathrm{C}, 2.51 \%$

*Corresponding author: e-mail address: aayday@sakarya.edu.tr 
Table 1. EPT hardening parameters

\begin{tabular}{cccccc}
\hline Sample code & Electrolytic solution & Impulse (V) & Pause (V) & Total time (s) & Cycle \\
\hline T4 & $\mathrm{Na}_{2} \mathrm{CO}_{3} 12 \%$ & 310 & 250 & $(3-3) \times 4-24 \mathrm{~s}$ & 4 \\
$\mathrm{~T} 5$ & $\mathrm{Na}_{2} \mathrm{CO}_{3} 12 \%$ & 310 & 250 & $(3-3) \times 5-30 \mathrm{~s}$ & 5 \\
$\mathrm{~T} 6$ & $\mathrm{Na}_{2} \mathrm{CO}_{3} 12 \%$ & 310 & 250 & $(3-3) \times 6-36 \mathrm{~s}$ & 6 \\
\hline
\end{tabular}

Si, $0.104 \% \mathrm{Mn}, 0.768 \% \mathrm{Cu}, 0.0444 \% \mathrm{Cr}, 0.060 \%$ $\mathrm{P}, 0.011 \% \mathrm{~S}, 0.0411 \% \mathrm{Mg}$ and Fe. The DI samples were machined from the bottom section of a $10 \mathrm{~cm} \times 60 \mathrm{~cm} \times 1.5 \mathrm{~cm}$ thick Y-block and were prepared at a $75 \mathrm{~mm} \times 179 \mathrm{~mm} \times 200 \mathrm{~mm}$ size. All specimens were polished with 120 to 1000 grit and cleaned with alcohol and dried before experimental surface treatments. A hole $3 \mathrm{~mm}$ in diameter was drilled up to a depth of $14 \mathrm{~mm}$ at the center of the specimen to house the thermocouple for temperature measurements. A K-type digital thermometer and data-logger were used to record temperatures. Sodium carbonate $\left(\mathrm{Na}_{2} \mathrm{CO}_{3}\right)$ solution was used as a heating and cooling source. The electrolytic plasma impulse values, pause values, treatment times and thermal cycling are listed in Table 1.

After surface hardening, the microstructure and composition were analyzed using a Nikon Eclipse L150 optical microscope (OM). The Rockwell hardness profiles of the surfaces were measured using a load of 150 kgf by Bulut Machine System (B.M.S.) tester. The cross-sectioned hardened layer was measured using a Future tech. tester with $200 \mathrm{~g}$ load and $10 \mathrm{~s}$. A linear ball-on-disk tribometer (CSM Tribometer) was applied to evaluate wear resistance of the samples under dry testing conditions with $0.5,1$ and $2 \mathrm{~N}$ normal load, $0.15 \mathrm{~m} \mathrm{~s}^{-1}$ sliding speed and $500 \mathrm{~m}$ sliding distance with the $\mathrm{Al}_{2} \mathrm{O}_{3}$ ball ( $6 \mathrm{~mm}$ in diameter) as the counter body. The wear tests were performed at an ambient temperature of about $30-35^{\circ} \mathrm{C}$ and $50-60 \%$ humidity. The typical morphologies of wear tracks were analyzed by OM. The profiles of wear tracks were investigated using a roughness Tencor P-6. The schematic wear modes are given in Fig. 1. The wear test used two different modes. First, only the modified surface was characterized and called "modified surface wear (MSW)," as shown in Fig. 1a. In the second mode, the wear mechanism was tested for the modified and non-modified surface resistance and called "composite surface wear (CSW)," as shown in Fig. 1b.

\section{Results and discussion}

The EPT scheme and the specimen geometry of the two regions after EPT treatment are shown in Fig. 2. The microstructure of the treated area was dependent on the heating and cooling cycles that took place
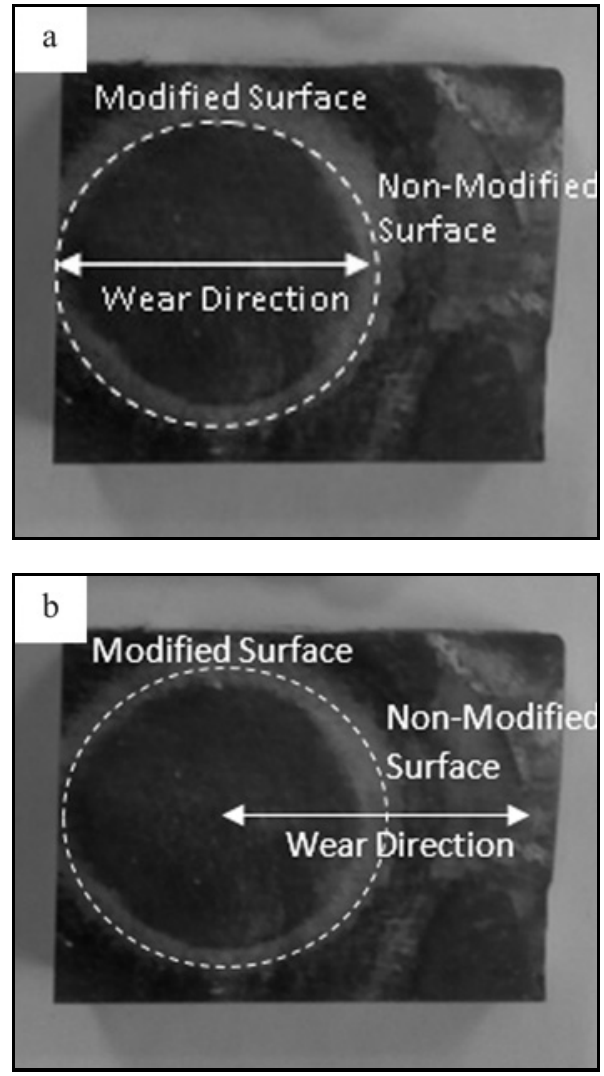

Fig. 1. Schematic wear modes: (a) Modified Surface Wear (MSW) and (b) Composite Surface Wear (CSW).

during the process. Modification with few thermal cycles showed two layers, the hardened zone and transition zone that can be seen schematically in Fig. 2a. Low magnification optical micrographs of the treated area of T4 samples are shown in Fig. 3. Increasing the number of thermal cycles changed the modified layer, which consisted of three layers: the remelted zone (RZ), the hardened zone (HZ) and the transition zone (TZ), as shown schematically in Fig. 2b. The low magnification optical micrographs of T6 samples are shown in Fig. 4.

Figure 3 shows the microstructure of the hardened layer of T4 samples. The hardened zones of T4 and T5 samples, which were modified with four and five thermal cycles, respectively, were coarse martensite with small quantities of retained austenite; the graphite nodules were unchanged (Fig. 3i), meaning 

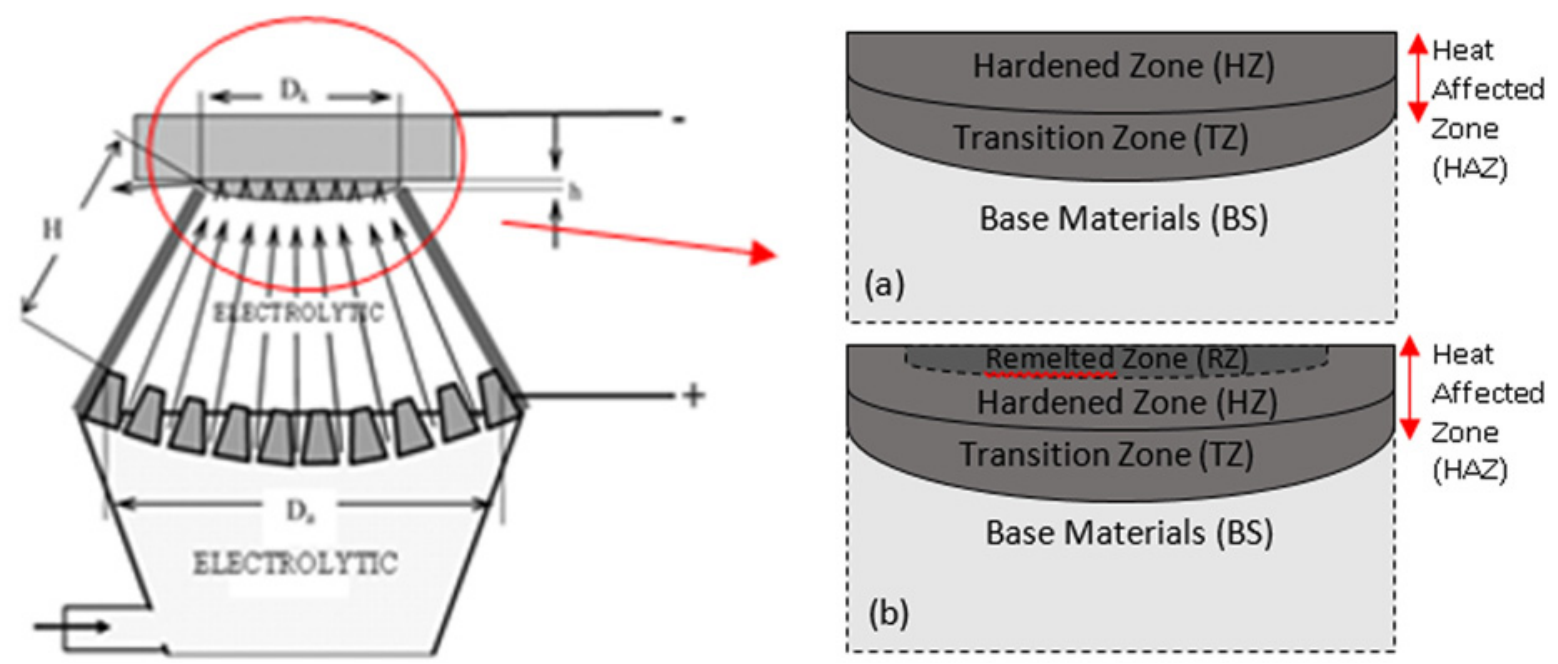

Fig. 2. The geometry of specimens for EPT-scheme showing two regions after surface treatment: (a) hardened sample areas and (b) remelted sample areas.
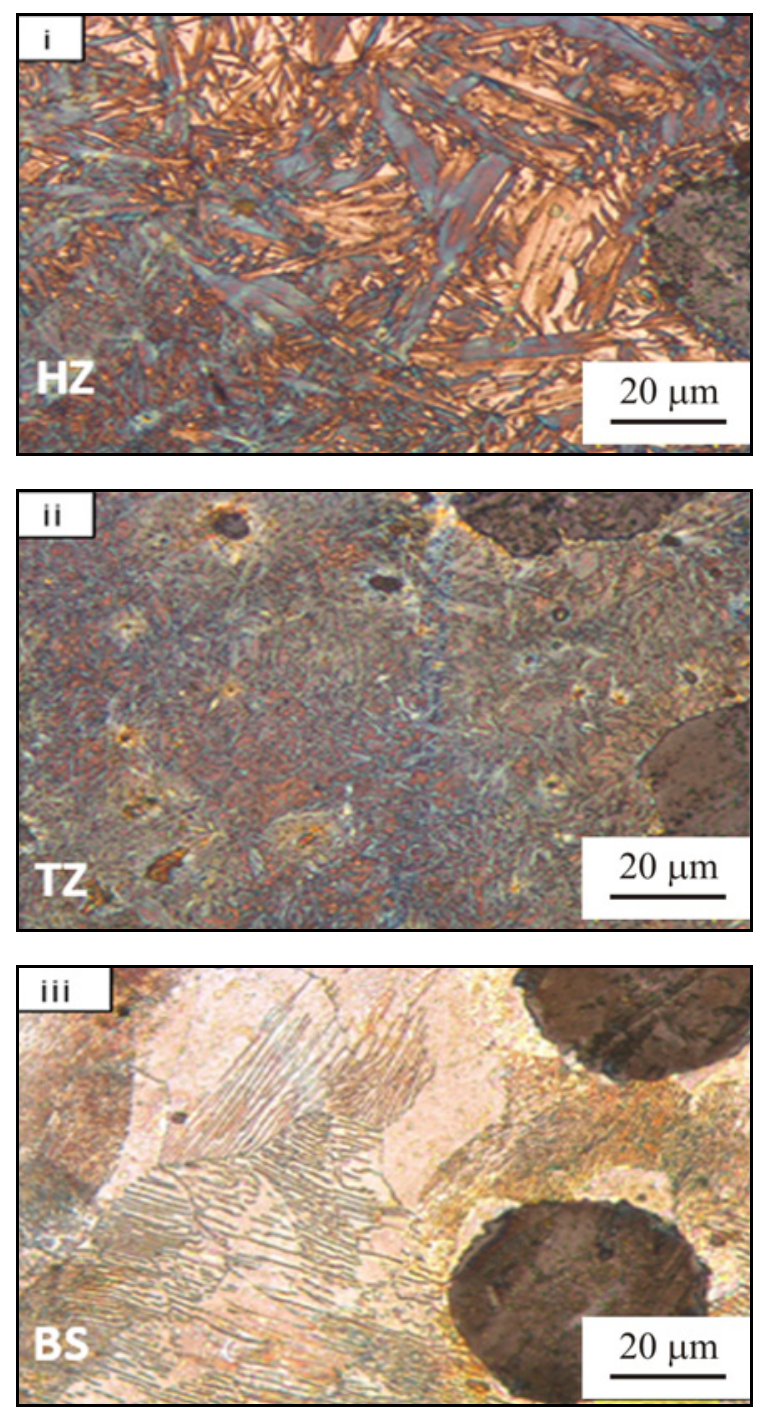

Fig. 3. Micrographs of the top hardened zone (i), transition zone (ii), and base materials (iii) of the T4 sample. that no melting occurred in the T4 samples. The TZ between the hardened zone and the base materials, which was characterized by retained austenite and upper and lower bainitic structures, can be seen in Fig. 3ii. The lower region of the TZ could not reach the critical austenitizing temperature, $A_{\mathrm{c} 1}$. For this reason, martensite was reduced, and bainite and retained austenite were present in the structure.

With an increased number of thermal cycles, one more layer was occurred on the surface (Fig. 2b). The details of the T6 sample micrographs are shown in Fig. 4. The figure shows transverse and longitudinal cross-sections through a sample modified with 6 thermal cycles. The microstructure in the melted zone was fine-grained and consists of austenite and ledeburite with martensite. In the melted zone, graphite was dissolved, and a harder and greatly refined ledeburitic microstructure was formed (Fig. 4i). It has been reported that with surface melting $[12,13]$, rapid selfquenching suppressed the re-formation of nodular cast iron in favor of the formation of white iron. In the region at the bottom of the melt layer, only partial dissolution occurred, and the graphite nodules, although decreased in diameter, had been retained $[2,13]$. The graphite nodules in the remelted zone did not form again after re-solidification due to the fast cooling rate [12]. The hardened zone was also characterized by little partial melting around the graphite nodules. The hardened zone consists of martensite, residual austenite and graphite spheroids (Fig. 4ii). The transition zone between the hardened zone and the base material consists of retained austenite, upper and lower bainite structures and graphite nodules (Fig. 4iii).

The layer thickness increased with the number of thermal cycles, shown in Fig. 5a. The modified layers were measured as 588, 3538 and $5014 \mu \mathrm{m}$. The crosssectional microhardness profiles of EPT modified DI 

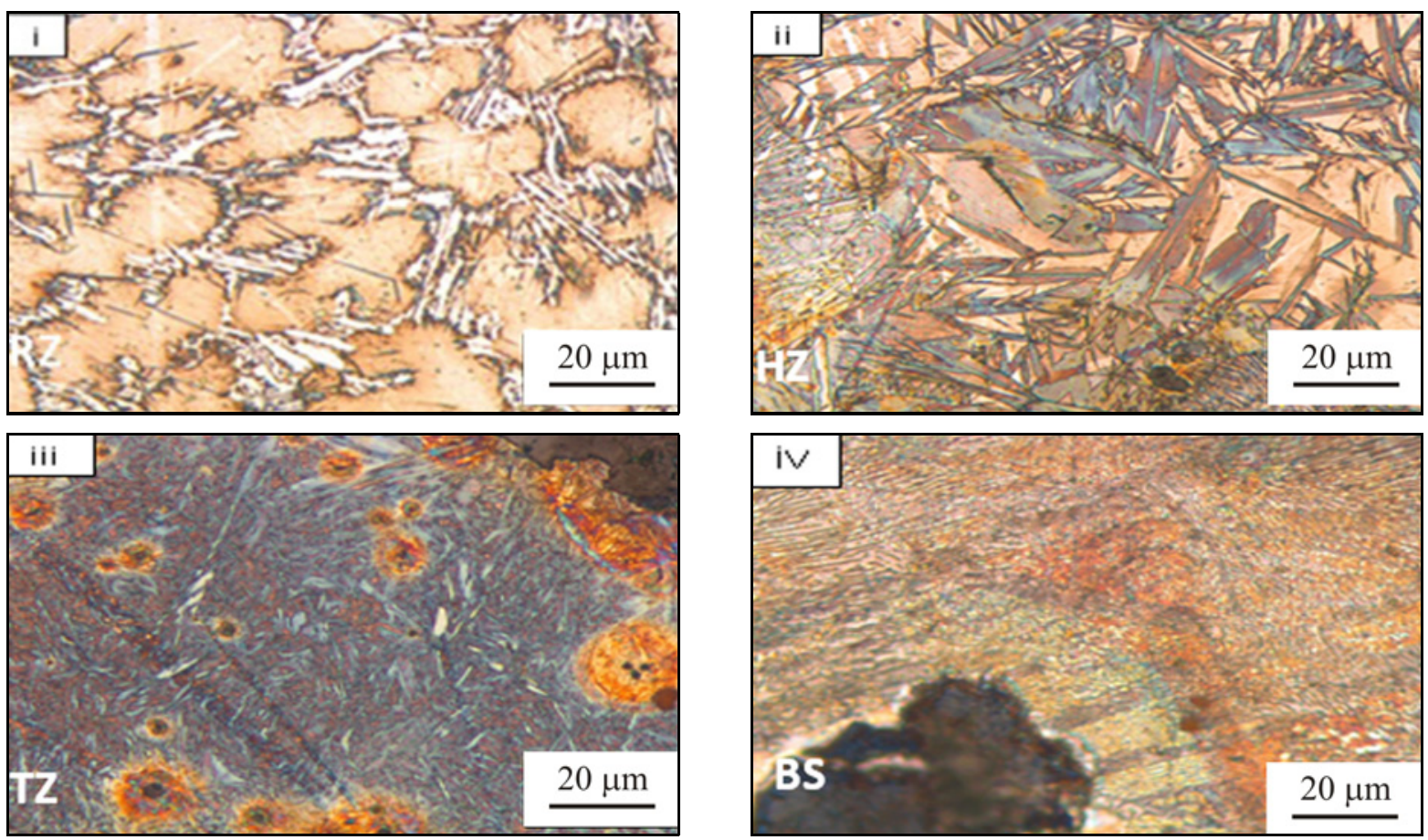

Fig. 4. Micrographs of the top remelted zone (i), hardened zone (ii), transition zone (iii) and base materials (iv) of the T6 sample.
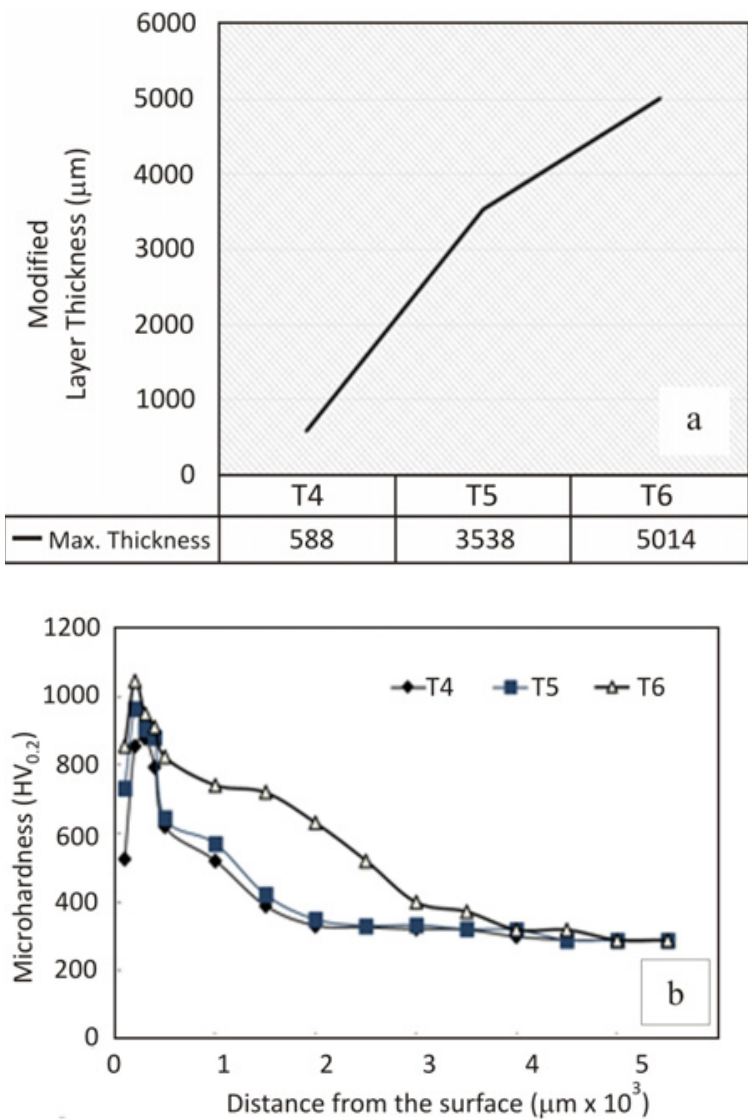

Fig. 5. (a) Layer thickness of EPT treated specimens and (b) microhardness along the depth of EPT treated specimens. are shown in Fig. 5b. The microhardness of untreated DI was $250 \pm 10 \mathrm{HV}_{0.2}$. The melted zone hardness of $\mathrm{T} 6$ was in the range of $1070 \mathrm{HV}_{0.2}$ and declined at the end of this region due to bainite and retained austenite. The martensitic zone of $\mathrm{T} 4$ and $\mathrm{T} 5$ samples was in the range of $980 \mathrm{HV}_{0.2}$, which was related to different surface morphologies caused by varied heating and cooling rates. The $\mathrm{HZ}$ showed a remarkable drop in hardness; at approximately $500 \mu \mathrm{m}$ from the surface, after $2 \mathrm{~mm}$, the hardness reached the value of the base materials.

The variations in the friction coefficient with wear loads of the MSA and CSA wear tests under dry sliding conditions are shown in Table 2. The linear wear test result is shown in Fig. 6, in which the wear loss was compared against the wear loads for the two-type wear mechanism tests, MSW and CSW. According to Fig. 6, it is clear that the wear loss of the T6 is much higher than that of the untreated samples, T4 and T5 samples for the MSW-type wear test. The samples with remelted structure (T6) had the poorest wear resistance even though their hardness was higher than that of the modified samples with few thermal cycles. Surface melting was found to result in the dissolution of the graphite nodules, which caused hard facing and could increase wear loss [14]. Furthermore, when the wear load increased, the wear loss increased.

It indicates that wear resistance of the CSW type wear mechanism improved by EPT hardened layers and graphite in ductile iron in non-modified areas. Compared with MSW, CSW type wear had high hard- 
Table 2. MSA and CSA wear test parameters

\begin{tabular}{|c|c|c|c|}
\hline \multirow{2}{*}{ Sample code } & \multirow{2}{*}{ Load $(\mathrm{N})$} & \multirow{2}{*}{$\frac{\text { Modified surface wear }}{\text { Friction coefficient, } \mu}$} & \multirow{2}{*}{$\frac{\text { Composite surface wear }}{\text { Friction coefficient, } \mu}$} \\
\hline & & & \\
\hline \multirow[t]{3}{*}{ Untreated ductile iron } & 0.5 & 0.328 & 0.347 \\
\hline & 1 & 0.233 & 0.233 \\
\hline & 2 & 0.220 & 0.220 \\
\hline \multirow[t]{3}{*}{$\mathrm{T} 4$} & 0.5 & 0.116 & 0.114 \\
\hline & 1 & 0.134 & 0.112 \\
\hline & 2 & 0.198 & 0.179 \\
\hline \multirow[t]{3}{*}{$\mathrm{T} 5$} & 0.5 & 0.147 & 0.116 \\
\hline & 1 & 0.174 & 0.117 \\
\hline & 2 & 0.196 & 0.175 \\
\hline \multirow[t]{3}{*}{ T6 } & 0.5 & 0.238 & 0.137 \\
\hline & 1 & 0.111 & 0.111 \\
\hline & 2 & 0.136 & 0.157 \\
\hline
\end{tabular}
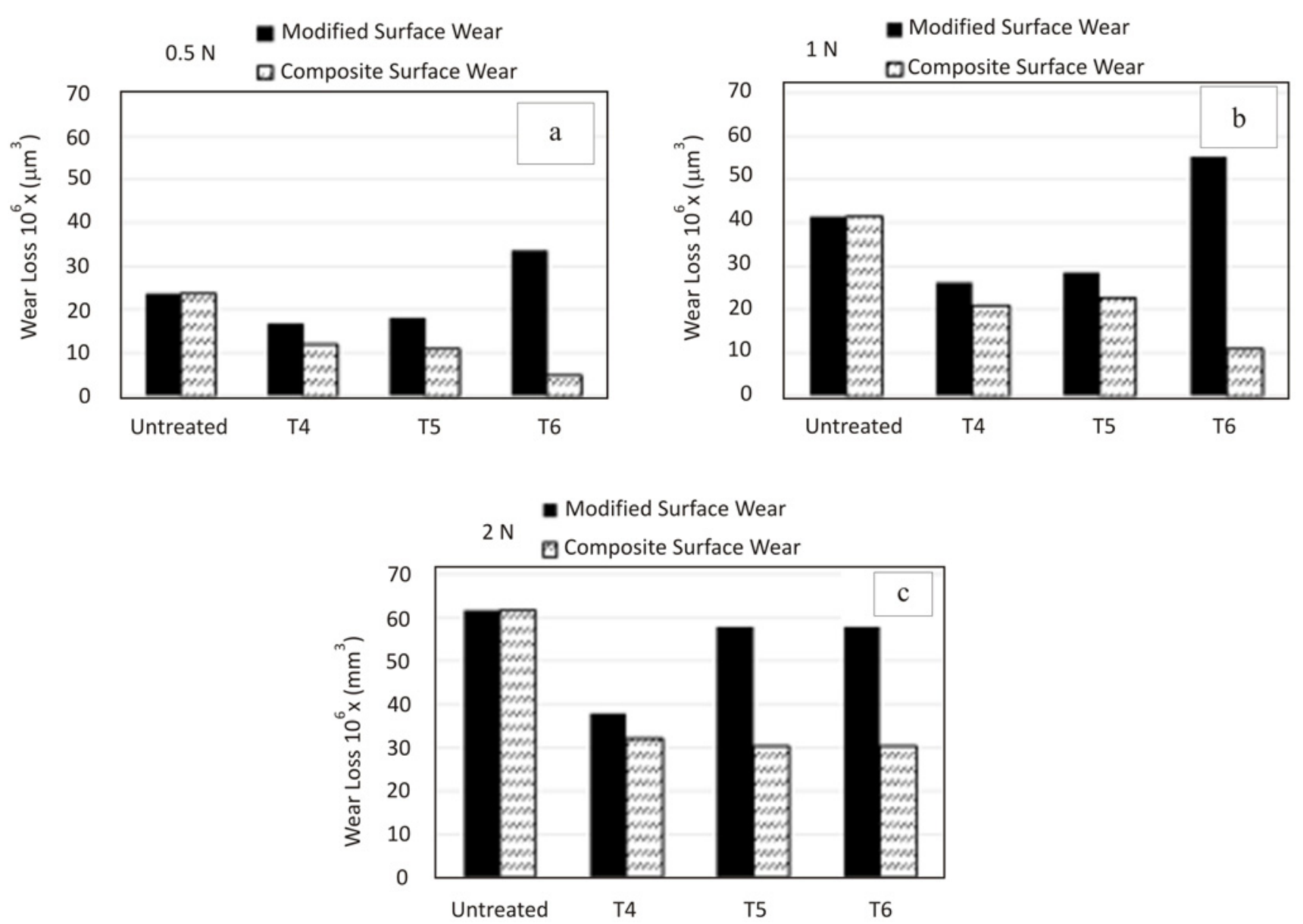

Fig. 6a-c. Wear loss of the untreated and modified DI under different loads, at the same sliding speed $\left(0.15 \mathrm{~m} \mathrm{~s}^{-1}\right)$ and sliding distance $(500 \mathrm{~m})$.

ness and good toughness in untreated surface areas. Graphite in the untreated DI areas was a solid lubri- cant that was beneficial for improving wear resistance. Figures $7 \mathrm{a}$,b show the wear rates of the all modi- 

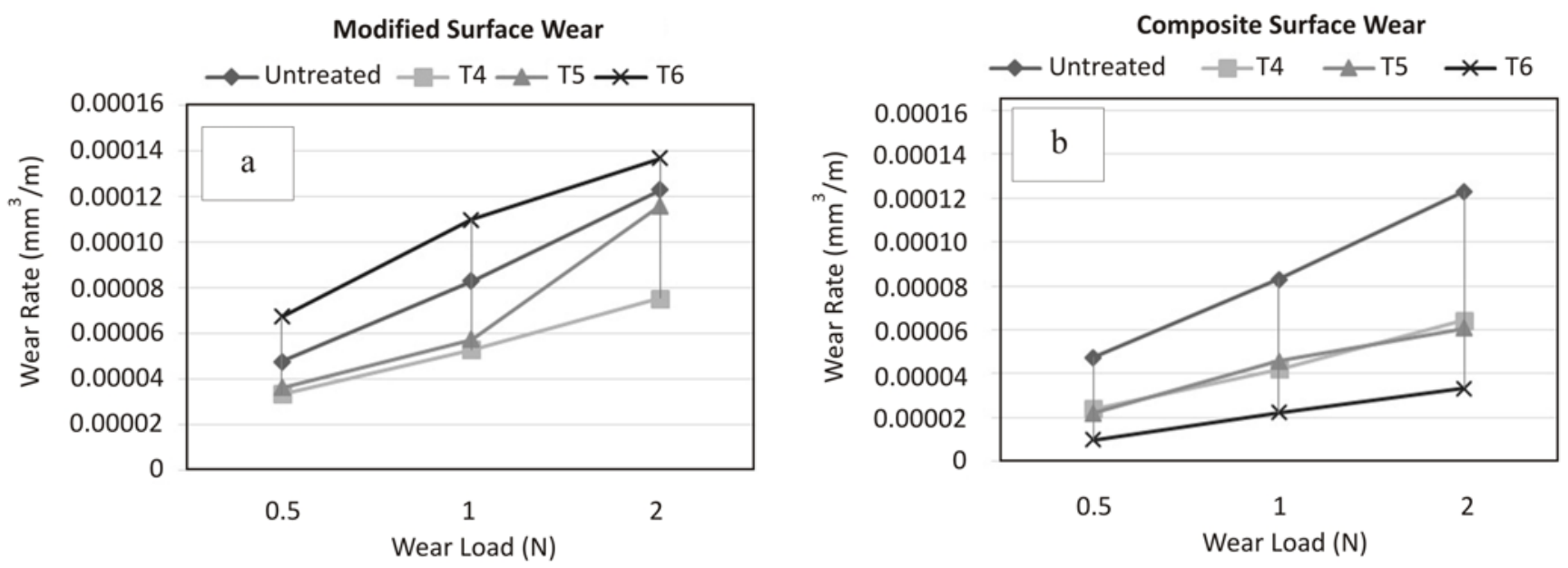

Fig. 7. Wear rates as a function of an applied load of all modified samples for (a) MSW, (b) CSW type wear tests, at the same sliding speed $\left(0.15 \mathrm{~m} \mathrm{~s}^{-1}\right)$ and sliding distance $(500 \mathrm{~m})$.
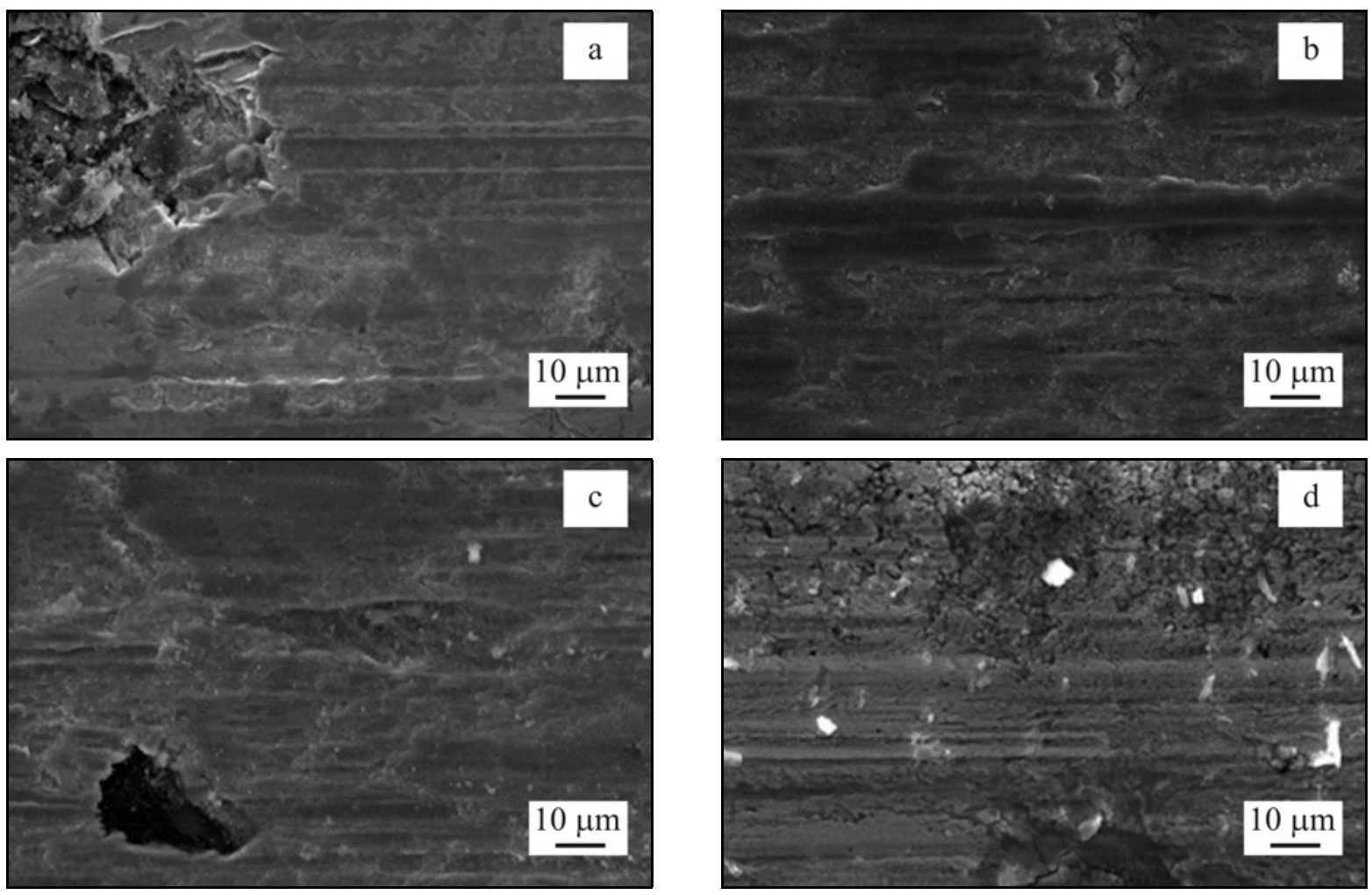

Fig. 8. SEM micrographs of MSW worn surface for the $0.5 \mathrm{~N}$ load: (a) untreated sample, (b) T4, (c) T5, and (d) T6.

fied samples as a function of applied load for a different type of wear tests. Increasing the load from 0.5 to $2 \mathrm{~N}$ noticeably increased the wear rate for all samples. The T4 sample shows the highest wear resistance for MSW type wear tests, being 4 times higher than that measured for the T6 sample, which was the hardest sample. Also, the untreated DI sample has a lower wear rate than the T6 sample for MSW-type wear tests. This phenomenon was mentioned before; the graphite nodules improve wear resistance [15].
A remarkable change was observed when the wear type changed to CSW, as shown in Fig. 7b. EPT treatment of DI gave an improvement for CSW wear resistance with increasing the thermal cycles. T6 samples show best wear resistance in the CSW type wear test. When compared to untreated samples, its wear rate decreased from $4.74 \times 10^{-5}$ (untreated sample) to $0.968 \times 10^{-5}$ (T6 sample) $\mathrm{mm}^{3} \mathrm{~m}^{-1}$ for $0.5 \mathrm{~N}$; decreased from $8.29 \times 10^{-5}$ (untreated sample) to $2.22 \times 10^{-5}$ (T6 sample) $\mathrm{mm}^{3} \mathrm{~m}^{-1}$ for $1 \mathrm{~N}$; 

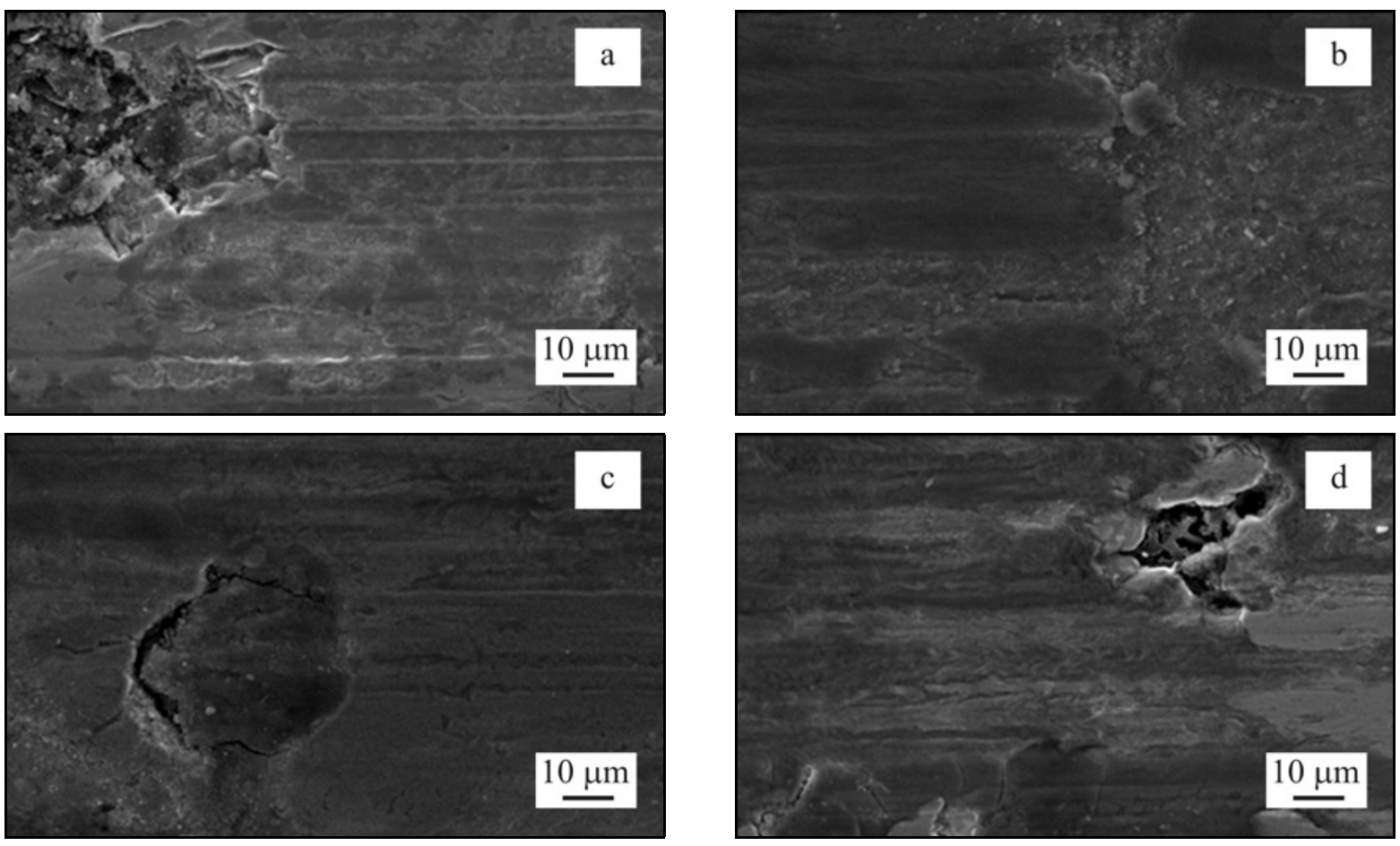

Fig. 9. SEM micrographs of CSW worn surface for the $0.5 \mathrm{~N}$ load: (a) untreated sample, (b) T4, (c) T5, and (d) T6.

and decreased from $12.3 \times 10^{-5}$ (untreated sample) to $3.32 \times 10^{-5}$ (T6 sample) $\mathrm{mm}^{3} \mathrm{~m}^{-1}$ for $2 \mathrm{~N}$.

SEM micrographs of the surface-treated samples before and after the wear test at a wear load of $0.5 \mathrm{~N}$ of MSW and CSW surfaces are shown in Figs. 8 and 9, respectively. The surfaces of DI, T4 and T5 samples revealed the appearance of abrasive wear with some plastic deformation (Figs. $8 \mathrm{a}-\mathrm{c}$ ). However, the surface of the T6 sample under MSW had a drastically worn surface with delaminated craters and abrasions. It is apparent from Fig. $9 \mathrm{~b}-\mathrm{d}$ that the modified worn surfaces of CSW layers are relatively smooth with only slight scratches and little adhesion. The graphite in the untreated area was a solid lubricant, which was beneficial for improving the wear behavior of the CSW mechanism [16].

\section{Summary and conclusions}

Electrolytic Plasma Treatment (EPT) was performed on ductile cast iron for different numbers of thermal cycles, and its effects on microstructure, hardness, and dry sliding wear were studied.

- The results showed that the materials modified by four thermal cycles (T4) and five thermal cycles (T5) had practically the same performance, showing improving mechanical properties after EPT. However, six thermal cycles (T6) resulted in differences in the microstructure, depth and wear rate. T4 and T5 samples are composed of coarse martensite and small quantities of retained austenite with unchanged graphite nodules, the T6 sample developed a melted zone that comprises austenite, ledeburite and martensitic structures.

- The depth of the modified zone depends on the temperature profile induced by the thermal cycles, as expected.

- The effective hardened layer of $0.2 \mathrm{~mm}$ to $1 \mathrm{~mm}$ for T4 and T5 samples, with a uniform microhardness between 350 and $980 \mathrm{HV}_{0.2}$, improved the wear resistance of ductile irons by MSW and CSW wear tests. However, the T6 sample's effective layer was 0.2 to $2.5 \mathrm{~mm}$, with a microhardness between 350 to $1050 \mathrm{HV}_{0.2}$, reducing the wear resistance to the MSW wear mechanism. The remelted zone showed a destructive effect because of the dissolved graphite. With the wear tests for the CSW mechanism, the hardest sample showed the best wear resistance.

\section{Acknowledgements}

The authors are grateful to Sakarya University, Turkey, and The E. O. Paton Electric Welding Institute, Ukraine for their great technical support.

\section{References}

[1] Soriano, C., Leunda, J., Lambarri, J., García Navas, V., Sanz, C.: Applied Surface Science, 257, 2011, p. 7101. doi:10.1016/j.apsusc.2011.03.059 
[2] Pagano, N., Angelini, V., Ceschini, L., Campana, G.: Procedia CIRP, 41, 2016, p. 987. doi:10.1016/j.procir.2015.12.131

[3] Slatter, T., Lewis, R., Jones, A. H.: Wear, 270, 2011 p. 302. doi:10.1016/j.wear.2010.11.003

[4] Heydarzadeh Sohi, M., Karshenas, G., Boutorabi, S. M. A.: Journal of Materials Processing Technology, 153-154, 2004, p. 199. doi:10.1016/i.jmatprotec.2004.04.307

[5] Fu, Y., Hu, J., Shen, X., Wang, Y., Zhao, W.: Nuclear Instruments and Methods in Physics Research B, 410, 2017, p. 207. doi:10.1016/j.nimb.2017.08.014

[6] Roy, S., Zhao, J., Shrotriya, P., Sundararajan, S.: Tribology International, 112, 2017, p. 94. doi:10.1016/j.triboint.2017.03.036

[7] Tyurin, Yu. N., Pogrebnjak, A. D.: Surface and Coatings Technology, 142-144, 2001, p. 293. doi:10.1016/S0257-8972 (01) 01207- 5

[8] Ayday, A.: Surface properties improvement of nodular cast iron modified by electrolytic plasma technology. [Ph.D. Thesis]. Sakarya, Sakarya University 2013, p. 28.

[9] Pogrebnyak, A. D., Kulmenteva, O. P., Kobzev, A. P., Tyurin, Yu. N., Golovenko, S. I., Boiko, A. G.: Technical Physics Letters, 29, 2003, p. 312. doi:10.1134/1.1573301
[10] Kwok, C. T., Man, H. C., Cheng, F. T.: Surface and Coatings Technology, 126, 2000, p. 238. doi:10.1016/S0257-8972 (00) 00533-8

[11] Pantelis, D. I., Bouyiouri, E., Kouloumbi, N., Vassiliou, P., Koutsomichalis, A.: Surface and Coatings Technology, 298, 2002, p. 125. doi:10.1016/S0257-8972(02) 00495-4

[12] Gulzar, A., Akhter, J. I., Ahmad, M., Ali, G., Mahmood, M., Ajmal, M.: Applied Surface Science, 255, 2009, p. 8527. doi:10.1016/j.apsusc.2009.06.011

[13] Benyounis, K. Y., Fakron, O. M. A., Abboud, J. H., Olabi, A. G., Hashmi, M. J. S.: Journal of Materials Processing Technology, 170, 2005, p. 127. doi:10.1016/i.jmatprotec.2005.04.108

[14] Podgornik, B., Vizintin, J., Thorbjornsson, I., Johannesson, B., Thorgrimsson, J. T., Martinez Celis, M., Valle, N.: Wear, 274-275, 2012, p. 267. doi:10.1016/i.wear.2011.09.005

[15] Ceschini, L., Campana, G., Pagano, N., Angelini, V.: Tribology International, 104, 2016, p. 342. doi:10.1016/i.triboint.2016.09.018

[16] Lu, J. Z., Luo, K. Y., Dai, F. Z., Zhong, J. W., Xu, L. Z., Yang, C. J., Zhang, L., Wang, Q. W., Zhong, J. S., Yang, D. K., Zhang, Y. K.: Materials Science and Engineering A, 536, 2012, p. 57. $\underline{\text { doi:10.1016/j.msea.2011.12.053 }}$ 